\title{
HOUÉE (Paul), Louis Joseph Lebret. Un éveilleur d'humanité
}

Paris, Éditions de l'Atelier, 1997, 219 p. (coll. « Mémoires d'hommes, mémoires de foi »)

\section{Michael Löwy}

\section{OpenEdition}

\section{Journals}

Édition électronique

URL : http://journals.openedition.org/assr/20653

DOI : $10.4000 /$ assr. 20653

ISSN : $1777-5825$

Éditeur

Éditions de l'EHESS

\section{Édition imprimée}

Date de publication : 1 juillet 2000

Pagination : 118-119

ISBN : 2-222-96691-4

ISSN : 0335-5985

Référence électronique

Michael Löwy, « HOUÉE (Paul), Louis Joseph Lebret. Un éveilleur d'humanité », Archives de sciences sociales des religions [En ligne], 110 | avril-juin 2000, document 110-67, mis en ligne le 19 août 2009, consulté le 21 septembre 2020. URL : http://journals.openedition.org/assr/20653 ; DOI : https:// doi.org/10.4000/assr.20653

Ce document a été généré automatiquement le 21 septembre 2020

(c) Archives de sciences sociales des religions 


\section{HOUÉE (Paul), Louis Joseph Lebret. Un éveilleur d'humanité}

Paris, Éditions de l'Atelier, 1997, 219 p. (coll. « Mémoires d'hommes, mémoires de foi »)

Michael Löwy

\section{RÉFÉRENCE}

HOUÉE (Paul), Louis Joseph Lebret. Un éveilleur d'humanité,Paris, Éditions de l'Atelier, 1997, 219 p. (coll. « Mémoires d'hommes, mémoires de foi »)

1 Cette biographie de Lebret retrace les principaux moments de la vie, de l'œuvre et de l'action de l'inspirateur du mouvement «Économie et Humanisme ». Comme la plupart des biographes de ce personnage hors pair, l'auteur part lui aussi des analyses d'Émile Poulat sur l'intransigeantisme catholique pour comprendre sa démarche. Si cette orientation a conduit l'animateur du mouvement de Saint Malo (action catholique maritime) vers le corporatisme et ensuite, vers le soutien à Pétain - l'A. cite une lettre au Maréchal de 1943 qui est assez parlante - il va aussi, dans un mouvement parallèle et contradictoire, l'attirer vers Marx, qu'il commence à étudier sérieusement dès 1938 . Dans un témoignage de 1945, Lebret raconte que le premier nom qu'il avait voulu donner à ce qui deviendra en 1942 "Économie et Humanisme» était «Centre International d'Études sur le Marxisme »! Cet intérêt - critique - pour le marxisme va marquer l'itinéraire intellectuel et politique du penseur dominicain (et chercheur au CNRS), indépendamment de ses prises de position - ou absences de positions politiques au cours des années.

2 Cela explique sa sympathie initiale pour la démarche d'Henri Desroches, et son soutien à l'ouvrage de ce dernier, Signification du marxisme (1949). C'est moins autour de ce livre que de l'option de Desroches pour le christianisme progressiste (proche du PCF) que va se dérouler leur conflit, suite à la condamnation, par le Saint-Office, de toute collaboration entre chrétiens et communistes. Comme l'observe l'A., ce décret romain 
va élargir le fossé entre Desroches, qui refuse la rupture du dialogue avec les communistes et Lebret, qui plaide pour une application souple et prudente de la décision du Vatican. Ce sera donc, en mai 1950, la séparation entre les deux amis et collaborateurs.

3 Par contre P.H. ne nous apprend rien sur le deuxième moment de tension grave dans «Économie et Humanisme»: l'affaire des prêtres-ouvriers. Cet événement, qui va ébranler toute la communauté dominicaine, et aussi Lebret - même s'il va, encore une fois, accepter de se plier à la discipline romaine - est pratiquement absent du livre.

4 Les projets de développement de Lebret pour le Tiers-Monde et l'IRFED occupent une place importante dans cette esquisse biographique. Pour mieux documenter cette partie, l'A. a demandé à des collaborateurs d'Économie et Humanisme en Afrique (Roland Colin, ancien directeur de cabinet de Mamadou Dia, du Sénégal) et en Amérique latine (Francisco Whitaker Ferreira, du Brésil) de témoigner. Le texte de Whitaker, secrétaire de la Commission Justice et Paix de l'Église catholique brésilienne montre que l'influence spirituelle et socio-religieuse de Lebret sur la jeunesse universitaire catholique et sur certaines figures catholiques comme l'écrivain Alceu Amoroso Lima ou l'évêque D. Helder Câmara a été bien plus importante que celles des enquêtes socioéconomiques conduites par un bureau d'études au nom impossible créé au Brésil en 1947 par Lebret - la "Société d'Analyses Graphiques et Mécanographiques Appliquées aux Complexes Sociaux", ou SAGMACS! Celles-ci n'ont pas eu beaucoup de conséquences pratiques; par contre, les écrits et les conférences de Lebret ont inspiré toute une génération de catholiques brésiliens qui va animer, au début des années soixante, un courant chrétien de gauche, précurseur de la théologie de la libération. 